\title{
SOME ASPECTS OF THE DIGITAL PRESENTATION OF FOLKLORE FESTIVALS
}

\author{
Kaloyan Nikolov \\ kaloyan.nikolov@iefem.bas.bg \\ Institute of Ethnology and Folklore Studies with Ethnographic Museum at the \\ Bulgarian Academy of Sciences, Sofia, Bulgaria
}

\begin{abstract}
The report explores the problems and peculiarities associated with the digital presentation of folklore festival heritage as a form of living heritage. The festival heritage in the Bulgarian lands is rich and varied in part due to our crossroads. Particular attention is paid to problematic issues and contradictions regarding the resources of cultural heritage and memory. In recent years, the preservation of the folklore heritage has become increasingly important and a multifaceted festival culture is being presented. The development of modern technology is a strong factor in finding the most appropriate and secure ways to preserve, digitize and represent culture and traditions.
\end{abstract}

Keywords: Information Technology; Social Networks; Cultural Heritage; Intangible Cultural Heritage; Video and Audio Archiving and Presentation; Folk Festivals

\section{НЯКОИ АСПЕКТИ НА АИГИТААНОТО ПРЕАСТАВЯНЕ НА ФОАКАОРНИ ФЕСТИВААИ}

\author{
Ка^оян Николов \\ Институт за етнология и фролк^ористика с етнографрски музей при \\ Българска акалемия на науките, София, България
}

Резюме: В статията са изследвани проблеми и особености, свързани с Аигиталното преАставяне на фролклорното феестивално наслелство като форома на живото наслелство. Фестивалното наслеАство в българските земи е богато и многообразно АонякъАе поради крьстопьтното ни местоположение. Особено внимание е отАелено на проблемни въпроси и противоречия, отнасящи се за ресурсите на културното наслеАство и паметта. През послеАните години запазването на фолклорното наслеАство приАобива все по-голямо значение и се представя все по-многостранна фестивална култура. Развитието на съвременните технологии е силен фоктор за тьрсене на най-удачни и сигурни начини за съхранение, циорровизиране и представяне на културата и тралициите..

КАючови Ауми: Инфоормационни технологии; социални мрежи; културно наслеАство; нематериално културно наслеАство; 
вилео и аудио арихивиране и презентиране; фролклорни фоестивали

Развитието на инорормационното общество несьмнено преминава през опознаването, запазването и практикуването на традициите на ^окалните общности. Както еАно човешко тяло се състои от различни органи, които изпьлняват различни функции за жизнеността му, така и глобалното общество се нужАае от ^окални общности, които Аа изпьлняват своите зальлжения, както в социален, така и в културен план. Несъмнено в навлизането на общество с изключително силна инфрормационна свързаност, ^окалните и глобалните проблематики са свързани в корелационни зависимости. Не са малко примерите, когато ^окални проблеми и практики се преврьщат в регионални или глобални. Запазването на традиционните култури и практики на ^ока^но и регионално ниво са ключов елемент за устойчиво развитие на обществените групи. С развитието на инорормационните технологии в Анешно време имаме шанс на Аостьпност на различни нива на познание. С развитието на транспортните възможности, миграциите и предвижването станаха приемливо Аостьпни. Урбанизационният процес през последното столетие придоби масивни измерения. Образуването на мегаполиси и смесването на различни вилове тралиционни култури започна по свой начин Аа образува нова гралска култура, нови културни пространства и нови културни комуникационни измерения.

\section{ТРАНСМИСИЯ НА ЕАЕМЕНТИ НА ЖИВО КУАТУРНО НАСАЕАСТВО}

Запазването на традиционните празнични и обреАни системи в навлизането на инорормационния век преминава през трансорормации, свързани с изменението и развитието на технологиите. Взаимстването на елементи на културно наследство увеличава своя ареал именно с възможността за бърз трансорер на познание. Поради отпалането на нуждата от практикуване на елементи на обредната традиционната култура, свързани с оцеляването на общностните групи, то трансмисията на тези елементи е поА въпрос. Голяма част от обреАните и празнични практики преминава в 
представяне преА публика, заучавани и демонстрирани от фолкклорни колективи от съответното населено място. Голяма част от тези обреАни и празнични практики се преработват и представят в обработени композиции на музикалното, песенно и танцово изкуство. Представянето преА местното население по време на традиционни събори, празници или оестивали е орорма на оцеляване, съществуване и трансмисия.

Живото наследство или терминологичен синоним на нематериално културно наследство изразява илентичността, както на всеки човек, така и на общности и националности. Специфииноотта на елементите на ^окала илентифицира културен ареал. Разширяването на съответния ареал воли Ао открояването на общи регионални културни елементи. Свързването на политико-административните региони в обща алминистративна структура през началото на 18 век води $А$ образуването на Аьржавни териториални граници. Исторически погледнато, именно образуването на дьржавните гранични територии водят Ао големи миграционни процеси и смесване на културни елементи.

През последните 60 гоАини се наблюАава нов поАхоА в представянето на традиционните културни празници и фрестивалните форми на пресъздаване и популяризиране на живото наследство. Аигиталната революция преАоставя нови технологични платорорми за презентиране, проследяване и отразяване на орестивалите с фролклорна насоченост. Моментното състояние на възможностите за презентиране, както за набиране на участници, така и за различни по естество публики, е свързано с ползването на каналите в социалните мрежи, специализирани новинарски емисии, общодостьпни отворени и специализирани мрежови платорорми, телевизионни и ралио канали, печатни изАания.

Специализирани межАународни платоорми за преАставяне на МежАународни фолклорни фестивали, за набиране на участници и разпределение на групи за участие. 
Има няколко организации, които поААържат WEB базирани платорорми за представяне на условията на различни межАународни фестивали и набиране на участници.

1. ClOFF1. Съвет на организаторите международни фолклорни фестивали с централа в Париж. Организацията е учрелена през 1970 голина и има 350 активни фестивала, презентирани за 2019 и 2020 година. Комуникацията межАу групите и организационния комитет се осъществява Аиректно или чрез сьзАалените национални структури. В много Аьржави има СъзАалени национални съвети към CIOFF, които коорАинират и селектират групи, които са преминали през квалифоикационни кръгове и имат способностите и възможностите $А$ п пеАставят местния фолк^ор на различни межлународни фестивали. Критериите за оценка на групите са обявени коректно и се слеАват стриктно. Фестивалите обикновено приемат за участие до 10-12 групи, което прави конкуренцията межлу групите голяма. Системата на приемане на участващи групи е насочена предимно за полупрофресионални групи за представяне на тралиционна култура в танцовото и песенно оролклорно изкуство. Обикновено групите са организирани в от еАномесечно Ао Авумесечно турне, С представяне в няколко фестивала в определен географоки регион. В повечето случаи концертните изяви на тези фестивали са платени или от местната алминистрация или чрез продаване на вхолни билети.

2. IOV-WORLD2. (International Organization of Folk Art) МежАународна организация за фолклорно изкуство, учредена през 1979 година в Австрия, по илея и инициатива на покойния Александър Вайгел. Неправителствена организация с нестопанска цел. Акредитирана организация с консултативни функции към МежАуправителствения комитет на Конвенцията за опазване на нематериалното културно наслеАство от 2003 гоАина КъМ ЮНЕСКО. За 2019 - 2020 гоАИна активните презерентирани 
На платформата са отразени всички координати на съответния организационен екип за директен контакт.

3. EAFF3. Европейска асоциация на фролклорните фрестивали, с централа в гр.Велико Търново, Бьлгария. Организацията е учрелена през 2007г. като неправителствена организация със нестопанска цел. Акредитирана организация с консултативни фуункции към МежАуправителствения комитет на Конвенцията за опазване на нематериалното културно наслеАство от 2003 година към ЮНЕСКО ${ }^{4}$. 3 а 2019 - 2020 година активните презерентирани феестивала са 455. Структурата за презентиране, набиране и селектиране на участващите групи е с централизирана активна апликационна електронна система, отговаряща на изискванията на съвременните методи за комуникация и обработка на Аанни. На WEB базираната платорорма са публикувани условията за участие на групите. Запозналите се групи с условията на съответния фрестивал, попьлват апликационна форма за изразяване на желанието си за участие и приемане на условията за провежлане. Предоставена инорормация от групата се изпраща Ао съответния организационен комитет за оценка и приемане или отказ от участие. ААминистративният персонал на WEB базираната платорорма увеАомява отговарящия за полалената апликационна фрорма за решението на организационния комитет, слеА което при одобрение се слеАват процеАурните стьпки за послелващо организиране на процеса за осъществяването на участието на групата. Платформата има изграцена информационна структура за презентиране, както в няколко социални мрежи, така и в телевизионна мрежа и новинарски пул, свързан с голям брой неспециализирани и специализирани инорормационни канали, с което подпомага трите етапа на процесите за организация -

\footnotetext{
${ }^{3}$ EAFF [www.eaff.eu , (Last view: 01.09.2019)].

${ }_{4}^{4}$ Convention 2003: Convention on the Disposal of the Intangible Cultural Heritage. Ratified by Bulgaria in 2006, promulgated in the State Gazette, No. 12 of 07.02.2006. [https://ich.unesco.org/doc/src/00009-BG-PDF.pdf, (Last view: 01.09.2019)] / [Конвенция 2003: Конвенция за опразване на нематериалното културно наследство. Ратифрицирана от България през 2006 г. обнародвана в Аържавен вестник, бр.12 от 07.02 .2006 г.].
} 
предварителна организация, провежлане и отразяване на събитията. Повечето феестивали от системата на ЕАФФ са бюАжетно самофинансирани. Концертните изяви са със свободен Аостьп. Критериите за участващите групи са отворени за всички възрастови групи, фрестивалите са двустранно насочени за изучаване на местните култури и забележителности и представената култура от участващите групи.

EAFF е обеАинение межАу повече от 70 организационни комитета, които също имат свои WEB базирани платорорми на преАставяне на организираните си фрестивали.

\section{ОТВОРЕНИ УЕБ БАЗИРАНИ ПААТФОРМИ В БЪАГАРИЯ}

\section{ЗА ПОПУАЯРИЗИРАНЕ НА ФЕСТИВААИ}

FEST.BG5 ${ }^{5}$ е най-голямата отворена мелия за фрестивали и празници в Бьлгария, която преАставлява WEB базирана платорорма за популяризиране на всякакъв вил фестивали и събития. Платорормата е със своболен Аостьп, като организационните екипи на фестивалите сами предоставят желаната инорормация за публикуване на организираното събитие. Представени са 743 събития от разнородни жанрове, като голяма част от събитията са с фро^к^орен характер.

Организирани секции на платорормата:
- Новини за фрестивали
- Прелложи събитие
- Общо тьрсене по периоли
- Изкуство - 419 събития
- Тралиции - 222 събития
- Кулинарни - 98
- Аруги събития - 33 събития
- Природа и спорт - 31 събития
- Празници - 6 събития
- Платорормата има и английска версия.

${ }^{5}$ FEST_BG [https://fest-bg.com, (Last view: 01.09.2019)]. 
К^ьстер "Фестивалите в България" е бенефициент по Проект "Развитие, укрепване и интернационализация на Кльстер "Фестивалите в България" Аоговор BG16RFOP002-2.009-0030, фринансиран от Оперативна програма "Иновации и конкурентноспособност" 2014-2020, съфинансирана от Европейския съюз чрез Европейския фонА за регионално развитие

SABORI.BG6 6 е уеб базирана платформа за популяризиране на фестивали и събития структурирани с няколко направления:

- Фолк^орни фрестивали, събори и панаири

- Coфpра с веселба - тематични фролклорни феестивали

- Аитература, изкуство и изложби

- Кино и театьр

- Религиозни и храмови празници

- Музикални и танцови прояви

- П^аващи празници

Предоставена е информация за събитието, контакти за врьзки, снимков материал. Изградена е интерактивна карта за бърз достьп Ао база по региони.

- Търсене по дати на провежАани събития

- Аопьлнителни секции за бърз Аостьп.

- Най-посещавани - автоматизирана система за инорормация на потребителите за най- много посещавани страници от базата със събития

- Събития с конкурсен характер

- Магия, цветове усещания - 3464 отразявания на събития

- Номинирани събития - избрани събития на принципа на посещаемост

- Непознатата Бьлгария

- Стоте национални обекта

- Календар на събитията

6 Portal of Non-profit Association: "Bulgarian Holidays" [https://www.sabori.bg/, (Last view: 01.09.2019)] / [Портал на САружение с илеална цел: „Празниците на Бьлгария"]. 
П^аторормата има и английска версия и е насочена, както за набиране на публики, така съзАаване на контакт на фолклорни групи с организаторите на фолклорните фестивали за допускане $А$ участие в избрано от тях събитие.Платорормата се подАьржа от САружение с илеална цел: „Празниците на България“ с предсеАател Емил Бакиш.

Посочените уеб базирани платдрорми за предоставяне на инфрормация за организираните фролклорни фрестивали имат Аигитален архив на минали събития и предоставят инорормация за предстоящи събития.

Архивирането на конкретна селектирана инорормация от изминалото събитие не предоставя научна база за изследване на процесите на запазване, пресьздаване на елементите на културното наслелство, а само отбелязва тяхното наличие. Съществуват няколко организации, които чрез използване на модерните аудио визуални среАства, записват, изльчват на живо и архивират концертните изяви по време на фестивалите, изготвят се Аокументални ффилми и се изльчват по телевизионни канали.

\section{MЕАИЙНА CPЕАА}

- ТВ Кана^ Аестинация, изпраща телевизионен екип за заснимане и отразяване на фолклорни фестивали, като слеА монтаж и обработка се изльчват. ТВ АЕСТИНАЦИЯ е затворен кана^, който може $а$ а се наблюдава само от абонатите на кабелен и сателитен оператор BULSAT. Не подАьржат отворена система за своболен Аостьп или публикуване на изработените орилми в платорорма за вилео сполеляне с отворен Аостьп.

- ТВ Кана^ СънРайз Маринов. Музикална компания СънРайз Маринов оперира собствен телевизионен канал, като по него се изльчват изпь^нения, както на продресиона^ни оркестри, певчески и танцови формации, така и направени видео кАипове на самодейни фолк^орни групи. Отразяване на фол^к^орни фестивали се прави еАин или Ава пьти гоАишно на организираните от компанията оестивали. 
- TB Kaна^ EuroFolk7, c Euro Folk Academy е базирана вьв Велико Търново и се управлява от компания, която освен телевизионния канал продуцира 24 сеАМични телевизионни фолклорни преАавания, които се изльчват по наА 20 самостоятелни телевизионни местни канала. Изработват се Аокументални фрилми за състояли се фролк^орни фрестивали. Концертните Изяви Се ИзАъчват На живо в НяколКО СОцИаАнИ И вИАеО платформи сьс свободен Аостьп, като архивни копия могат $\Delta$ व се намерят и могат да бъдат гледани. Телевизионният канал се изльчва в кабелните мрежи в България и в Интернет сьс своболен Аостьп на tv.eurofolk.com. ВиАео-архивьт на компанията сьдьржа наА 7000 часа концертни изпьлнения, обичаи, виАеоклипове, Аокументални фрилми, събирани и произвежАани от повече от 15 гоАини. Архивьт преАставлява интерес от научна глеАна точка за изследване и наблюдения. Част от материалите са използвани за канАиАатстването на отАелни елементи за включване в Българския национален регистьр на НКН и Националната система „Живи човешки съкровища - България"8.

Рейтинговите телевизионни канали не отразяват провежлането на фролклорни фрестивали. Рядко може да се виАи, и то само в новинарска емисия, кратко отразяване на събитие, различно от фрестивалите в Копривщица и Рожен.

\section{ЗАКАЮЧЕНИЕ}

През изминалите 10 години организирането на фолклорни прояви бележи значителен рьст. Всяко читалище има за важна залача в културната си програма $а$ а организира и проведе фолклорен фрестивал, кулинарно събитие и честване на празник. Важно е $а$ се

\footnotetext{
7 EuroFolkAcademy [https://tv.eurofolk.com/, (Last view: 01.09.2019)].

8 Living Human Treasures - Bulgaria - The National Register is available on the website of the Ministry of Culture [https://www.treasuresbulgaria.com, (Last view: 01.09.2019)] / [Живи човешки съкровища - България - Националния регистьр е Аостьпен на страницата на Министерството на културата].
} 
наблегне не само на организирането и провеждането, а и на отразяването на събитието. Аокументирането, оставянето на цидрова следа или научното теренно наблюдение на мероприятието биха засилили значението му, както за преките възложени цели, така и в научен п^ан с коректно описание и архивиране на инорормацията за бълещото поколение(Lyubenova, 2017).

Организирането на специализирани курсове по етнография на читалищно ниво и коорАинацията на изгралена мрежа от инорорматори и връзка с Научните архиви на ИЕФЕМ-БАН би $А$ Ио нова инорормационно активна картина на измененията на елементите на културно наследство, провежланите фестивали фрорми на презентация и трансмисия, така и опресняването на Аигиталния архив „Бьлгарско фролк^орно наследство" (Bogdanova, 2010), (Mateeva, 2010).

\section{AИTEPATYPA / REFERENCES}

Bogdanova, Galina, (2010). Digital Archive "The Bulgarian Folklore Heritage": Software Assurance and Data Protection. b. 3-4, pp. 30-40 (In Bulgarian) / [БогАанова, Галина 2010 Аигитален архив „Българското фролклорно наслеАство": програмно осигуряване и защита на Аанни. К.3-4 стр. 30-40]

Lyubenova, Milena, (2017). Preservation of the Intangible Cultural Heritage: From Living Practice to the Archive - Preserving the Cultural Heritage - Ideas and Practices p.132 - 137 ISBN 978-954-322-908-6 Ed. BAS "Prof. Marin Drinov, 2017. (In Bulgarian) / [^юбенова, Милена, 2017, Съхранение на нематериалното културно наследство: от живата практика $А$ архива - Опазване на културното наслеАство - илеи и практики стр.132 - 137 ISBN 978-954-322-9086 ИзА. БАН „Профр. Марин Аринов“, 2017.]

Mateeva, Vanya, (2010). Digital Archive "Bulgarian Folklore Heritage": Folklore Studies - Bulgarian Folklore b. 3-4, рр. 11-29 (In Bulgarian) / [Матеева, Ваня 2010 Аигитален архив „Българското фролклорно наслеАство“: фролклористични изслеАвания - Български фролклор к 3-4 стр.1 1-29] 


\section{КУАТУРНО-ИСТОРИЧЕСКО НАСАЕАСТВО: \\ ОПАЗВАНЕ, ПРЕАСТАВЯНЕ, АИГИТААИЗАЦИЯ}

CULTURAL AND

HISTORICAL

HERITAGE

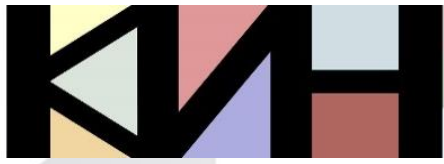

PRESERVATION PRESENTATION

DIGITIZATION
Материалите в сборника са обект на авторско право. Разрешава се безвъзмезАното ползване на техни електронни/ хартиени копия само за лична употреба или обучение, при пь^но цитиране на текущата страница и слеА писмена декларация от цитиращия за Аипса на търговски намерения. За копиране пол Аруга фрорма, препубликуване или публикуване на сървъри се изисква писмено разрешение и/или заплащане.

() Авторски колектив, 2019 Технически реАактори: Николай Ноев Калина Сотирова-Вълкова Ка^оян Николов

\section{Editors}

Galina Bogdanova Vanya Mateeva

This work is subject to copyright. Open and free of charge use of digital/hard copies of publications is granted only for personal or educational use, with full citation of the current page, and after written declaration of the quoting side for not-commercial Intention. For any other reproducing types, republishing, photocopying, recording, or any other storage retrieval system/ server written permission and/or fee is required.

(C) Authors` Group, 2019

Technical editors:

Nikolay Noev

Kalina Sotirova-Valkova

Kaloyan Nikolov

Научна поредица: том 5, брой 2 (7)/2019

Science series: vol. 5 , issue $2(7) / 2019$

www.math.bas.bg/vt/kin

ISSN: 2367-8038 